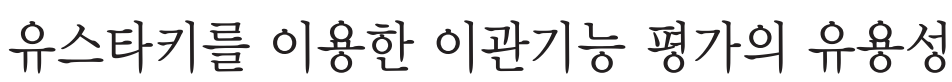

동아대학교 의과대학 이비인후-두경부외과학교실

박상후 · 김상준 · 이동근 · 강명구

\title{
Efficacy of Evaluating Eustachian Tube Function by Using Eustachi
}

\author{
Sang Hoo Park, MD, Sangjun Kim, MD, Dong Kun Lee, MD, PhD, and Myung Koo Kang, MD, PhD \\ Department of Otorhinolaryngology-Head and Neck Surgery, College of Medicine, Dong-A University, Busan, \\ Korea
}

\begin{abstract}
- ABSTRACT -
Background and Objectives: Since Eustachian tube (ET) plays an important role in the development of middle ear disease, evaluating the function of ET is important. Valsalva maneuver is frequently used, but does not reflect the physiological function. Inflation-deflation test assess both active and passive function of the ET, so it can reflect the physiological function. In our clinic, we use device named Eustachi ${ }^{\mathrm{TM}}$ to evaluate ET. In this study, we evaluated ET in patients with perforated eardrums using Valsalva maneuver, inflation-deflation test and Eustachi to evaluate the efficacy of Eustachi in assessing ET function. Materials and Methods: 51 dry perforated eardrums were selected. Patients were divided into 3 groups according to the result of the inflation-deflation test; Type A, ET opens in both positive and negative pressure; Type B, ET opens in either positive or negative pressure; Type C, ET dose not open in neither positive nor negative pressure. All patients performed Valsalva maneuver and Eustachi application. Techniques were statistically analyzed and compared. Results: When analyzing whether Valsalva was possible according to the type of inflation-deflation test, there were statistical differences when comparing type A, B and type $A, C(p=0.000,0.024)$. There was no statistical difference between type $B$ and $C(p=1.000)$. When analyzing the result of Eustachi according to the type of inflation-deflation test, there was no statistical difference between type A and $\mathrm{B}(\mathrm{p}=1.000)$, while there were statistical differences when comparing type $\mathrm{A}, \mathrm{C}$ and type $\mathrm{B}, \mathrm{C}(\mathrm{p}=0.048,0.030)$. Conclusions: Compared with the results of inflation-deflation test, Eustachi can evaluate ET more physiologically than Valsalva maneuver. (J Clinical Otolaryngol 2021;32:40-46)
\end{abstract}

KEY WORDS: Eustachian tube · Valsalva maneuver · Chronic otitis media.

\begin{abstract}
서 론
중이는 고실, 이관, 유돌부로 구성되어 서로 연결되 어 있다. 이 중 이관은 상기도의 확장된 부분으로 중이 와 비인강을 연결하며, 평상시에는 주로 닫힌 상태로 유 지되어 중이는 외부로부터 폐쇄된 구조를 가진다. 이관 은 능동적, 수동적 반응으로 일시적으로 열리면서 중이

강의 압력과 대기압을 같게 유지한다. 이관은 연하, 하 품, 재채기 등의 생리적 현상 후 연골부 주위의 근육들 이 수축하여 능동적으로 열리며, 중이와 비인두 사이 최 소 $20 \mathrm{mmHg}$ 압력차가 발생하면 수동적으로 열릴 수 있다. 이관은 환기 기능 외에도 중이 내 점액 등의 분비 물을 배출하는 정화 기능, 비인강의 해로운 물질의 역 류로부터 중이를 보호하는 방어 기능을 수행한다. ${ }^{1)}$ 이
\end{abstract}

논문접수일: 2021년 1월 4일 / 논문수정일: 2021년 1월 26일 / 심사완료일: 2021년 6월 4일

교신저자: 강명구, 49201 부산광역시 서구 대신공원로 26 , 동아대학교 의과대학 이비인후-두경부외과학교실

전화: (051) 240-5428·전송: (051) 253-0712·E-mail: mgkang6108@naver.com 
관부전의 병인을 알기 위해 다양한 이관기능검사를 시 행하지만, 아직까지 임상적으로 주로 이용되는 특정검 사법은 없다. ${ }^{2)}$ 고식적인 이관통기검사로 Valsalva법, Toynbee법, Politzer법, 카테터 삽입법 등이 있으나, 이 런 검사법은 단순히 이관개폐에 대한 유무를 알아보는 방법으로 이관의 기능적 이상을 확인하지는 못한다. 생 리적인 방법으로는 고막운동성계측법(tympanometry), 부하음압검사법(inflation deflation test), 음향이관측정 법(sonotubometry), 근전도검사, 배출기능검사 등이 있 다. ${ }^{3)}$ 최근 비강으로의 일정 압력을 통해 이관기능을 평 가할 수 있는 Tubomanometry가 높은 재현성과 정확도 를 나타내는 것으로 알려져 있다. ${ }^{4)}$ 하지만 아직까지 생 리학적으로 이관의 기능을 정확하게 평가하고, 이관기 능장애를 진단할 수 있는 검사방법은 없다고 알려져 있 다. ${ }^{5)}$ 부하음압검사법은 음압과 양압에 대한 이관기능을 모두 평가할 수 있기 때문에, 이관기능을 생리적으로 잘 반영할 수 있는 검사법인 동시에 고막이 천공된 경우에 도 시행할 수 있다는 장점이 있다. ${ }^{6}$ 본원에서는 고막의 천공이 있는 환자의 이관기능을 평가하기 위해 Valsalva 법, 부하음압검사법과 함께 Eustachi ${ }^{\mathrm{TM}}$ (Exercore LLC, USA)라는 기구를 사용한다(Fig. 1). Eustachi는 비강을 통해서 이관으로 인위적으로 일정 압력의 공기 를 넣어주면서 동시에 환자에게 침을 삼키게 함으로써 이관의 개구를 돕는 기구로 외국에서는 소아의 급성 중 이염, 삼출성 중이염 치료에 도움을 주기 위해 사용되고 있다. 저자들은 강한 압력을 통해 억지로 이관을 열어주 는 Valsalva법과는 다르게 Eustachi를 이용한 이관기능 평가는 환자가 침을 삼키면서 자연스럽게 이관이 열릴 때 일정 압력의 공기가 들어가게 되므로 이관의 기능을 Valsalva법보다 더 생리적으로 반영할 수 있다고 예상 하였다. 또한 현재 정확성과 유용성이 높은 검사인 부하 음압검사는 임피던스 측정기계가 필요하며, 정확한 검 사를 위해 숙련된 검사자가 필요한 반면 Eustachi를 이 용한 이관기능 평가는 기구만 있으면 간단하게 검사를 시행할 수 있다는 장점이 있다. 이에 본 연구에서는 고 막의 천공이 있는 만성 중이염 환자의 이관기능을 부하 음압검사, Valsalva법, Eustachi를 이용한 총 3가지 방 법으로 평가하고, 결과의 상관관계를 분석해 Eustachi 를 이용한 이관기능 평가가 유용한지, 또한 유용하다면

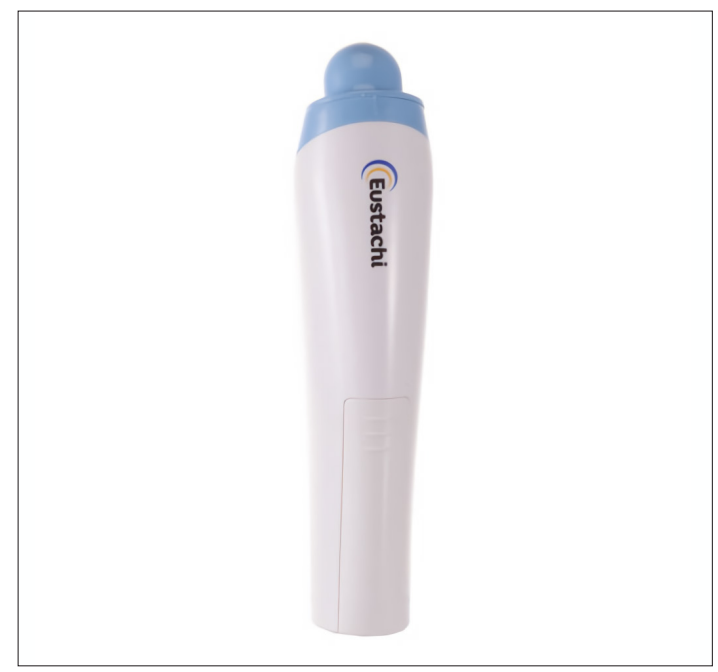

Fig. 1. Appearance of Eustachi.

Valsalva법보다 생리적인 기능을 더 잘 반영하는지를 확인하여 Eustachi의 유용성을 관찰하고자 한다.

\section{대상 및 방법}

본 연구는 동아대학교병원 임상연구 심의위원회의 승 인(DAUHIRB-20-190)을 얻은 후 진행되었다. 2019 년 5월부터 2020년 2월까지 본원 외래를 방문한 환자 중 만성 중이염을 진단 받은 환자의 진료 기록을 후향적 으로 분석하였다. 총 환자 48 명, 51 례의 귀가 연구 대상 이 되었다. 내원 당시 이루가 있거나 상기도 염증이 있 던 환자 및 만성 중이염 수술을 받고 천공이 재발된 환 자는 대상에서 제외하였다. 또한 진료 기록에서 3가지 이관기능 측정방법의 결과가 모두 표기되어 있지 않은 환자도 대상에서 제외하였다. 성별 분포는 남자가 17 명 (35.4\%), 여자가 31명(64.6\%)이었고, 연령분포는 21세 에서 79세로 평균 53세였다.

\section{Valsalva법에 의한 이관기능 평가}

환자에게 입을 다물고 자신의 코를 잡고 코를 풀 때처 럼 스스로 힘을 주게 하였다. 고막이 천공된 경우 이관 을 통해 공기가 중이강으로 들어가면 천공된 고막을 통 해서 공기가 새어나가는 것을 확인할 수 있다. 환자 1명 당 Valsalva법을 총 3회 시행하였고, 천공된 고막이 있 
는 쪽의 외이도를 양측에 구멍이 딿려 있는 긴 튜브로 막은 후 공기가 새어 나오는 소리의 유무를 확인하였다. 3 회 중 2회 이상 소리가 나오는 경우를 Valsalva $(+), 3$ 회 모두 소리가 나지 않는 경우를 Valsalva(-)로 분류하 여 기록하였다. 환자가 Valsalva법을 제대로 시행하지 못해 Valsalva(-) 결과가 나오는 것을 방지하기 위해 환 자에게 Valsalva법의 안내문을 주고 30 분 동안 충분히 연습 시킨 후 결과를 기록하였다.

\section{부하음압검사를 통한 이관기능 평가}

부하음압검사는 $-600 \mathrm{daPa}$ 에서 $+400 \mathrm{daPa}$ 까지 의 압력을 측정할 수 있는 고막운동성계측기(GSITympstar II Middle Ear Analyzer of America)를 이 용하여 Miller방법에 의한 이관기능검사를 이용하여 시 행되었다. ${ }^{7)}$ 외이도에 직접 양압과 음압을 가한 후 환자 에게 침을 5 차례 삼키게 한 후 중이강에 남아 있는 압력 을 고막운동성계측기로 측정하여 이관의 기능을 측정하 였다. 이관의 기능이 정상이라면 연하운동을 할 때마다 이관이 열리면서 중이강에 남아 있는 압력은 $0 \mathrm{daPa}$ 로 떨어지게 되고, 이 결과를 이관이 열렸다고 정의하였다. 양압, 음압 모든 조건에서 이관이 열린 경우를 $\mathrm{A}$ 형, 양 압을 가했을 때는 이관이 열렸지만 음압을 가했을 때는 이관이 열리지 않은 경우를 B형, 모든 조건에서 이관이 열리지 않아 중이강에 남아 있는 압력이 있는 경우를 C 형으로 분류하였다(Fig. 2). 음압을 가했을 때는 이관이 열리고 양압을 가했을 때 이관이 열리지 않는 경우는 본 연구에서 관찰할 수 없었다.

\section{Eustachi를 이용한 이관기능 평가}

Eustachi는 비강을 통해서 비인두를 지나 이관으로 인위적인 일정 압력의 공기를 넣어주면서 동시에 환자 에게 침을 삼키게 함으로써 이관의 개구를 돕는 기구로 수동으로 작동하며 크기가 작아 휴대할 수 있다는 장점 을 가진다. 본 연구에서는 Eustachi를 이용하여 이관기 능을 평가하기 위해 먼저 환자에게 한 모금의 물을 머금 게 하고 입을 다물게 하였다. 천공이 없는 쪽의 코는 손 으로 막고 천공이 있는 쪽의 코에 Eustachi의 입구를 삽 입한 후 전원을 누르면 일정한 압력의 공기가 Eustachi 의 입구에서 나오게 된다. 검사자는 환자의 천공된 고
막이 있는 쪽의 외이도를 양측에 구멍이 뚫려있는 긴 probe로 막으면서 동시에 probe의 반대편 끝을 자신의 귀에 넣는다. 이후 공기가 비강을 통해서 들어갈 때 환 자에게 머금은 물을 삼키라고 하고 환자의 천공된 고막 이 있는 쪽의 probe를 통해 공기가 새어 나오는지 소리 의 유무를 확인한다. 3 회 중 2 회 이상 소리가 나오는 경 우를 Eustachi(+), 3회 모두 소리가 나지 않는 경우를 Eustachi(-)로 분류하여 기록하였으며, 결과에 대한 의 견이 2 명 이상의 검사자에서 일치한 경우만 유의미한 대상으로 선정하였다.

\section{통계적 분석}

분석프로그램은 SPSS 24.0(IBM Corp. Released 2016. IBM SPSS Statistics for Windows, Version 24.0. Armonk, NY: IBM Corp.)을 사용하였으며, 모 든 통계적 유의성은 0.05 로 설정하였다. 분석방법은 Type에 따라 Valsalva 가능 여부(+/-) 및 Eustachi 검 사(+/-)의 차이를 알아보기 위해 교차분석 및 Fisher's exact test를 실행하였으며, 부하음압검사의 결과인 Type A, B, C의 3가지 유형을 2가지씩 비교할 때는 교 차분석 및 Fisher's exact test를 실시하였고, $p$-value는 본페로니 수정(Bonferroni correction)을 하여 적용하 였다.

\section{결 과}

부하음압검사 결과, $\mathrm{A}$ 형은 26례(50.1\%), B형은 23례(45.1\%), C형은 2례(4.8\%)였다. Valsalva법 결 과, Valsalva(+)는 31례(60.8\%), Valsalva(-)는 20례 (39.2\%)였다. Eustachi를 이용한 이관기능 평가에서 Eustachi(+)는 46례(90.2\%), Eustachi(-)는 5례(9.8\%) 였다. 부하음압검사 유형에 따라 Valsalva 가능 여부 를 비교 · 분석하였을 때 $\mathrm{A}$ 형과 $\mathrm{B}$ 형은 통계적으로 차 이가 있었고 $(\mathrm{p}=0.000), \mathrm{A}$ 형과 $\mathrm{C}$ 형을 비교하였을 때 도 통계적으로 유의한 차이가 확인되었다 $(\mathrm{p}=0.024)$. 반 면, B형과 C형은 통계적으로 유의한 차이가 확인되지 않았다( $\mathrm{p}=1.000)$ (Table 1), 부하음압검사 유형에 따라 Eustachi 검사의 가능 여부를 비교 분석하였을 때 $\mathrm{A}$ 형 과 $\mathrm{B}$ 형은 통계적으로 유의한 차이가 없었고 $(\mathrm{p}=1.000)$, 

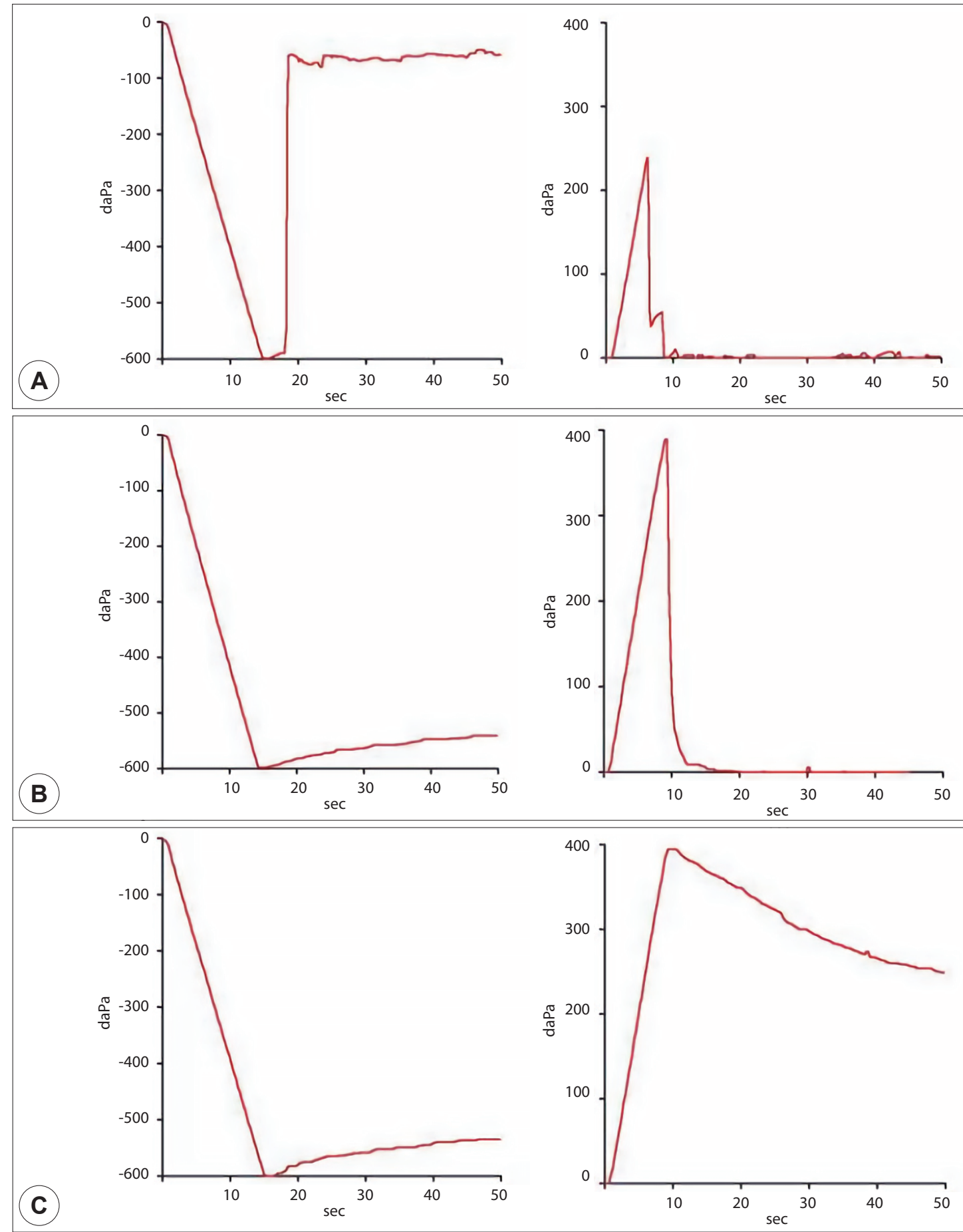

Fig. 2. Classification of Eustachian tube according to the result of inflation deflation test. A: Type A, Eustachian tube opens in both negative and positive pressure B: Type B, Eustachian tube dose not open in negative pressure but opens in positive pressure C: Type C, Eustachian tube dose not open in neither negative nor positive pressure. 
Table 1. Correlation between Valsalva maneuver and Inflation deflation test

cases

\begin{tabular}{cccc}
\hline Group & Type A & Type B & Type C \\
\hline Valsalva(+) & 25 & 6 & 0 \\
Valsalva(-) & 1 & 17 & 2 \\
\hline
\end{tabular}

$A$ vs $B, P=0.000$.

$A$ vs $C, P=0.024$.

$B$ vs $C, P=1.000$.

$\mathrm{A}$ 형과 $\mathrm{C}$ 형, $\mathrm{B}$ 형과 $\mathrm{C}$ 형 사이에서 통계적으로 유의한 차 이가 확인되었다 $(\mathrm{p}=0.048, \mathrm{p}=0.030$ )(Table 2). B형에 서 Valsalva와 Eustachi를 이용한 이관기능 평가 결과를 분석하였을 때 Valsalva(+), Eustachi(+)는 6례(26.1\%), Valsalva(+), Eustachi(-)는 0례(0\%), Valsalva(-), Eustachi(+)는 16례(69.6\%), Valsalva(-), Eustachi(-) 는 1례(4.3\%)였다(Table 3).

\section{고 찰}

이관은 상기도의 확장된 부분으로 큰 연골부와 작은 골부가 만나 형성되며, 중이와 비인강을 연결한다. 골 부는 외측의 $1 / 3$ 을 구성하며, 중이강으로 열리고 내측 $2 / 3$ 은 연골부로 구성되며, 인두편도의 외측의 비인강으 로 열린다. 항상 열려 있는 골부와는 달리 연골부는 평 상시에는 닫혀 있지만, 이관 개구에 가장 중요한 역할 을 하는 구개범장근(Tensor veli palatine muscle)과 구 개거근(Levator veli palatine muscle)이 부착되어 있기

Table 2. Correlation between Eustachi and Inflation deflation test

cases

\begin{tabular}{cccc}
\hline Group & Type A & Type B & Type C \\
\hline Eustachi (+) & 24 & 22 & 0 \\
Eustachi (-) & 2 & 1 & 2 \\
\hline
\end{tabular}

$A$ vs $B, P=1.000$.

$A$ vs $C, P=0.048$.

$B$ vs $C, P=0.030$.

Table 3. Comparison of Valsalva maneuver and Eustachi in Type B patients

cases

\begin{tabular}{ccc}
\hline Eustachi $^{- \text {Valsalva }}$ & $(+)$ & $(-)$ \\
\hline$(+)$ & 6 & 16 \\
$(-)$ & 0 & 1 \\
\hline
\end{tabular}

때문에 연하, 하품, 재채기 시 일시적으로 열리면서 이 관의 능동적 기능을 담당한다. 이관의 기능 부전은 만성 중이염을 포함하는 중이 질환의 중요한 원인일 뿐만 아 니라, ${ }^{8)}$ 고실 성형술의 술 후 성적을 예측할 수 있는 중 요한 인자로 알려져 있다. Choi 등)은 고실성형술 Type 1 을 시행한 환자의 술 전 이관기능을 부하음압검사법 을 이용하여 평가한 후 술 후 청력 개선 정도를 비교하 여 이관기능이 좋은 환자에서 술 후 청력 개선도 좋다는 결과를 보고하였다. Shimada 등 ${ }^{10}$ 의 연구에 따르면 이 관기능과 유양동 함기화의 정도를 비교했을 때 이관 기 능이 저하된 환자에서 유양동의 함기화 정도가 떨어진 다고 보고하였고, Holmquist ${ }^{11)}$ 는 만성 중이염 환자 중 술 전 좋은 이관기능이 확인된 환자의 유양동이 함기화 가 잘 관찰된다고 보고하였다. 이런 연구 결과들을 통해 서 이관기능의 정확한 평가가 중이 질환의 치료 및 예후 판정에 있어 중요한 역할을 한다는 것을 확인할 수 있 다. 이관기능을 평가하기 위해서 다양한 검사법이 제시 되어 왔다. 제시된 여러 검사법은 이관의 구조적 기능을 평가하거나, 이관의 생리적인 기능을 평가하는 방법으 로 분류할 수 있다. ${ }^{12)}$ 고식적인 이관통기검사로 이전부 터 사용된 Valsalva법, Toynbee법, Politzer법, 카테터 삽입법 등은 시행하기 간편하고, 이관의 개폐 유무를 알 아볼 수는 있지만, 이관의 생리적인 기능과는 무관하다 고 알려져 있다. ${ }^{13)}$ 내시경이 도입된 이후, 비디오 내시 경을 이용하여 비강을 통해서 환자가 침을 삼킬 때 이관 의 인두 개구부의 모양 및 움직임을 직접 관찰하는 검사 법도 이관의 기능을 평가하는 유용한 방법이지만, 다른 검사들과 비교해서 침습적이라는 단점이 있다. ${ }^{14)}$ 부하 음압검사법은 외이도를 통해서 양압과 음압을 주고 환 자에게 침을 삼키게 한 이후의 잔존 압력을 고막운동성 계측기로 측정하는 검사법으로 다른 검사들과는 다르게 이관의 생리적인 기능을 평가할 수 있는 검사법이다. ${ }^{15)}$ 또한 양압과 음압에 대한 이관기능을 모두 측정할 수 있 고, 침습적이지 않으며 이루가 있는 고막에서는 유용성 이 떨어진다고 보고되어지지만 고막에 천공이 있는 경 우에도 시행할 수 있다는 장점이 있다. $\left.{ }^{6}\right)$ 그렇기에 본 연 구에서는 내원 당시 이루가 있거나 상기도 염증이 있던 환자는 대상에서 제외하였다.

Shimada 등 ${ }^{10)}$ 은 이관기능과 유양동의 함기화 정도를 
비교하는 연구에서 본 연구와 마찬가지로 부하음압검사 법의 결과에 따라 환자를 세 그룹으로 분류하였다. 양 압, 음압을 가했을 때 이관이 모두 잘 열리는 경우인 A 형과 양압을 가했을 때는 이관이 열리지만 음압을 가했 을 때는 이관이 열리지 않는 경우인 B형에서 이관의 평 균 개구 압력, 유양동의 크기, 고실성형술 시행 후 고막 의 재천공 빈도를 비교하였을 때 통계적으로 유의한 차 이가 나타나지 않았다. 반면, $\mathrm{A}$ 형과 $\mathrm{C}$ 형을 비교했을 때 는 이관의 평균 개구 압력, 유양동의 크기, 고실성형술 시행 후 고막의 재천공 빈도 모두 통계적으로 유의한 차 이를 나타내었다. 이러한 결과를 바탕으로 부하음압검 사법의 결과에서 $\mathrm{B}$ 형으로 확인된 이관은 이관 기능장애 가 있는 $\mathrm{C}$ 형보다 이관 기능이 정상인 $\mathrm{A}$ 형에 더 가깝다 고 생각해볼 수 있다.

본 연구에서는 부하음압검사 유형에 따라 Valsalva 가능 여부를 비교 분석하였을 때 $\mathrm{A}$ 형과 $\mathrm{B}$ 형, $\mathrm{A}$ 형과 $\mathrm{C}$ 형 사이에서는 통계적으로 유의한 차이가 확인되었지 만, $\mathrm{B}$ 형과 $\mathrm{C}$ 형은 통계적으로 유의한 차이가 확인되지 않았다. 이러한 통계 결과는 Valsalva 가능 여부로 부하 음압검사 유형을 비교했을 경우, 이관 기능이 정상인 A 형과 이관기능장애가 있는 $\mathrm{C}$ 형의 이관 기능에는 차이 가 없고 또한 $\mathrm{B}$ 형의 이관 기능이 $\mathrm{A}$ 형보다 $\mathrm{C}$ 형에 더 가 깝다는 의미로 해석된다. 반면, 부하음압검사 유형에 따 라 Eustachi 검사의 가능 여부를 비교 분석하였을 때는 $\mathrm{A}$ 형과 $\mathrm{B}$ 형은 통계적으로 유의한 차이가 없었고, $\mathrm{A}$ 형과 $\mathrm{C}$ 형, $\mathrm{B}$ 형과 $\mathrm{C}$ 형 사이에서 통계적으로 유의한 차이가 확인되어 Shimada 등미의 연구와 일치하는 결과를 나타 내었다. 이러한 통계적 결과를 토대로 Eustachi를 이용 한 이관기능 검사가 Valsalva법보다 부하음압검사법의 결과와 더 비슷하여 생리적인 이관기능을 평가하는 데 Valsalva법보다는 더 유용한 것으로 사료된다.

본 연구의 한계점으로는 대상이 51례로 적고, 객관 적인 결과를 확인할 수 있는 부하음압검사법과는 다르 게 고막의 천공을 통해서 소리를 들어야 하는 Valsalva 법, Eustachi를 이용한 이관기능 평가의 결과는 검사 자에 따라 주관적일 수 있다는 점이다. 평가의 객관성 을 최대한 확보하기 위해 동일한 환자에서 3회의 검사 를 시행하였고, 결과에 대한 의견이 2 명 이상의 검사자 에서 일치한 경우만 유의미한 대상으로 선정하였다. 이
런 한계점에 대해서는 향후 좀 더 많은 증례가 필요하 며, Valsalva법, Eustachi를 이용한 이관기능 평가의 결 과를 좀 더 객관적이고 쉽게 분류할 수 있는 기준이 세 워져야 할 것으로 사료된다.

\section{결 론}

부하음압검사 결과와 비교하였을 때 Eustachi를 이 용한 이관기능 평가가 Valsalva법보다는 더 생리적으로 이관의 기능을 평가할 수 있다. 또한 Eustachi는 휴대와 작동이 간편하기 때문에 고막운동성 계측기가 없는 경 우 간단하게 이관기능을 평가할 수 있을 것으로 사료된 다. 향후 더 많은 환자군을 대상으로 연구를 시행할 필 요가 있으며, Valsalva법, Eustachi를 이용한 이관기능 평가의 결과를 좀 더 객관적이고 쉽게 분류할 수 있는 기준이 필요하다.

중심 단어 : 유스타키오관, 발살바 조작법, 만성 중이염.

This study was funded by Department of Otorhinolaryngology-Head and Neck Surgery, College of Medicine, Dong-A University.

\section{REFERENCES}

1) Bluestone CD. In: Bluestone Maria Bra, editor. Eustachian tube: structure, function, role in otitis media. B.C. Decker; 2005. p. 4-62.

2) Smith ME, Blythe AJC, Baker C, Zou CC, Hutchinson PJA, Tysome JR. Tests of eustachian tube function: the effect of testing technique on tube opening in healthy ears. Otol Neurotol 2017;38(5):714-20.

3) Holmquist J, Olén L. Evaluation of Eustachian tube function. J Laryngol Otol 1980;94(1):15-23.

4) Schröder S, Lehmann M, Korbmacher D, Sauzet O, Sudhoff $\mathrm{H}$, Ebmeyer J. Evaluation of tubomanometry as a routine diagnostic tool for chronic obstructive Eustachian tube dysfunction. Clin Otolaryngol 2015;40(6):691-7.

5) Todd NW. There are no accurate tests for eustachian tube function. Arch Otolaryngol Head Neck Surg 2000;126(8): 1041-2.

6) Kurien R, Chrisolyte S, Rupa V. Inflation-deflation test as a predictor of aditus patency in patients with chronic suppurative otitis media. Indian J Otolaryngol Head Neck Surg 2009; 61(3):169-72.

7) Miller GF. Eustachian tube function in normal and disease ears. Arch Otolaryngol 1965;81:41-8.

8) Yücetürk AV, Unlü HH, Okumuş M, Yildiz T, Filiz U. The 
evaluation of eustachian tube function in patients with chronic otitis media. Clin Otolaryngol Allied Sci 1997;22(5):44952.

9) Choi SH, Han JH, Chung JW. Pre-operative evaluation of Eustachian tube function using a modified pressure equilibration test is predictive of good postoperative hearing and middle ear aeration in type 1 tympanoplasty patients. Clin Exp Otorhinolaryngol 2009;2(2):61-5.

10) Shimada S, Yamaguchi N, Honda Y. Eustachian tube function and mastoid pneumatization. Acta Otolaryngol Suppl 1990;471:51-5.

11) Holmquist J. Middle ear ventilation in chronic otitis media. Arch Otolaryngol 1970;92(6):617-23.
12) Doyle WJ, Swarts JD, Banks J, Casselbrant ML, Mandel EM, Alper CM. Sensitivity and specificity of Eustachian tube function tests in adults. JAMA Otolaryngol Head Neck Surg 2013;139(7):719-27.

13) Sharp M. The manometric investigation of tubal function with reference to myringoplasty results. J Laryngol Otol 1970;84(6):545-51.

14) Kwon JH, We JH, Cho JH, Park GH, Goh EK. Efficacy of the Eustachian tube function test using by rigid videoendoscopy. Korean J Otolaryngol-Head Neck Surg 2007;50(11):983-8.

15) Bluestone CD, Doyle WJ. Anatomy and physiology of eustachian tube and middle ear related to otitis media. J Allergy Clin Immunol 1988;81(5 Pt 2):997-1003. 